\title{
DESENVOLVIMENTO DE HIDROGÉIS PARA LIBERAÇÃO CONTROLADA DE ANTIBIÓTICOS NO TRATAMENTO DE INFECÇÕES
}

\author{
J. E. S. NOGUEIRA ${ }^{1}$, A. G. SILVA JUNIOR ${ }^{1,2}$, M. D. L. OLIVEIRA ${ }^{1,2}$ e C.A.S. \\ ANDRADE ${ }^{1,2}$.
}

\footnotetext{
${ }^{1}$ Departamento de Bioquímica, Universidade Federal de Pernambuco, Recife/PE

${ }^{2}$ Programa de Pós-Graduação em Inovação Terapêutica, UFPE, Recife/PE E-mail para contato: jonathas20168@gmail.com
}

\begin{abstract}
RESUMO - A resistência a antimicrobianos é um problema atual e recorrente em todo mundo. Apesar da existência de diversos métodos terapêuticos utilizados no tratamento de infecções, novas abordagens são necessárias, visando não apenas a redução de custos, mas principalmente a de apresentar uma atividade mais efetiva. O alginato de sódio é um polímero natural obtido a partir de algas marrons, o qual quando em contato com cátions divalentes como o $\mathrm{CaCl}_{2}$, produz hidrogéis o qual é possivel inserir agentes ativos como antibióticos, visando uma liberação mais prolongada. O presente trabalho desenvolveu hidrogéis de alginato homogêneos, com o antibiótico eritromicina encapsulado visando uma avaliação da melhor síntese: com ou sem o cloreto de cálcio. Os resultados obtidos evidenciaram uma liberação crescente e prolongada do antibiótico realizada pelo hidrogel contendo o $\mathrm{CaCl}_{2}$, atingindo um pico de liberação em 7 dias. O hidrogel produzido pode ser considerado uma alternativa inovadora no tratamento de infecções tópicas, utilizando a menor quantidade de agente antimicrobiano possível.
\end{abstract}

Palavras-chave: Alginato; Eritromicina; Hidrogel.

\begin{abstract}
Antimicrobial resistance is a recurring problem in worldwide level. New approaches are necessary aiming the effective infection treatment, using innovative procedures. Sodium alginate is a natural polymer obtained from brown algae that produces hydrogels when in contact with divalent cations such as $\mathrm{CaCl}_{2}$. These hydrogels can be used to encapsulate active agents such as antibiotics for a longer release. The present work developed homogeneous erythromycin encapsulated alginate hydrogels, aiming evaluating which hidrogel present better release: with or without calcium chloride. Obtained results showed an increasing and prolonged release of erythromycin presented by $\mathrm{CaCl}_{2}$ added hydrogel. Produced hydrogels are an innovative alternative in topical infections treatment, using small amounts of antibiotic agent.
\end{abstract}

Keywords: Alginate; Erythromycin; Hydrogel. 


\section{INTRODUÇÃ̃O}

Infecções associadas a microrganismos em ferimentos como os ocasionados por úlceras e acidentes físicos apresentam como primeira escolha o uso de antibióticos. Entretanto, devido ao uso indiscriminado e sem uma terapêutica correta desses agentes, transformaram a resistência a antimicrobianos um problema global (MOTA et al., 2005). Logo, buscam-se novas formas e estratégias para minimizar os danos e gastos desnecessários, visando melhorar sua farmacocinética e eficácia utilizando materiais inovadores, assim propiciando um aprimoramento na janela terapêutica concomitante com a diminuição dos quadros de resistência (SILVEIRA et al., 2006).

Polímeros naturais têm ganhado atenção na medicina devido às suas diversas aplicações, como na engenharia de tecidos e no desenvolvimento de materiais para a liberação controlada de fármacos (BHATIA, 2016). Um exemplo de polímero é o polissacarídeo alginato, obtido a partir de algas marrons (Fig. 1 a). Em comparação com polímeros sintéticos, o alginato é conhecido pela sua biocompatibilidade, biodegradabilidade, baixo custo e capacidade de formação de filmes e hidrogéis (Fig. 1 b) (MANJANNA, RAJESH e SHIVAKUMAR, 2013). Pode-se classificar os hidrogéis como agentes poliméricos altamente absorventes que possuem uma estrutura tridimensional distinta. Classificam-se ainda haja vista sua origem (natural ou sintética) e sua interação com o organismo (degradáveis ou não-degradáveis) (KOPEČEK e YANG, 2007). Dessa forma, o presente trabalho teve como objetivo o desenvolvimento de hidrogéis baseados em alginato de sódio para a liberação prolongada e controlada de eritromicina, visando controle na atividade antimicrobiana no tratamento de infecções, favorecendo indiretamente na redução dos índices de intoxicação causada por agentes antimicrobianos.

\section{MATERIAIS E MÉTODOS}

Alginato de sódio, eritromicina, cloreto de cálcio $\left(\mathrm{CaCl}_{2}\right)$ e água deionizada ultrapura foram utilizados no processo de produção do hidrogel. $200 \mathrm{mg} / \mathrm{mL}$ de alginato de sódio é adicionado a um béquer de $100 \mathrm{~mL}$, seguido da aplicação do solvente e agitação mecânica durante o tempo de cinco minutos. Em seguida, concentrações específicas de eritromicina foram adicionadas ao hidrogel pré-preparado, seguido novamente por agitação mecânica. A nível de comparação, nova amostra de hidrogel com antibiótico foi preparada com adição de $\mathrm{CaCl}_{2}(180 \mathrm{mM})$. Em seguida o hidrogel é imerso em um béquer com $15 \mathrm{~mL}$ de solvente para retirada de $2 \mathrm{~mL}$ do sobrenadante, havendo reposição de $2 \mathrm{~mL}$ de solvente puro logo em seguida. As análises foram realizadas em espectrofotômetro de duplo feixe (LABOMED, USA).

\section{RESULTADOS E DISCUSSÃO}

Após a confecção dos hidrogéis com o antibiótico eritromicina, foi feito o perfil de liberação dos mesmos em períodos de 24 horas durante um intervalo de até 12 dias, havendo a avaliação do hidrogel com e sem a adição de cloreto de cálcio como agente de ligação cruzada (cross-linking). 
Figura 1 - Alginato de sódio em pó (a) e o hidrogel de alginato produzido (b).

(a)

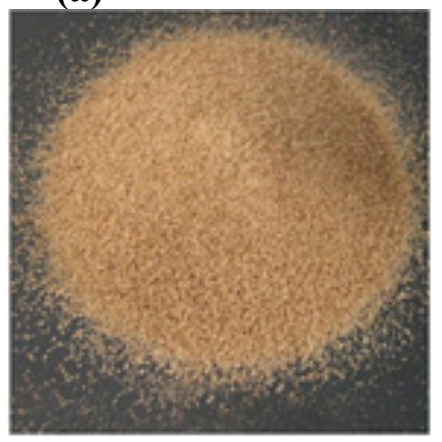

(b)

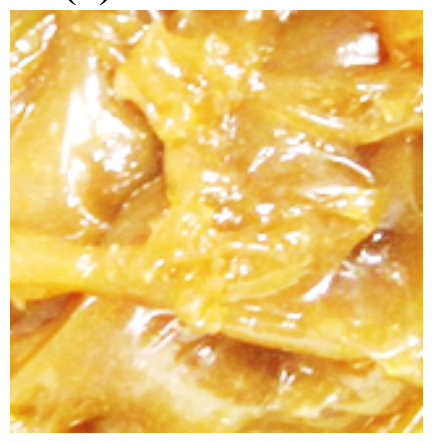

A eritromicina apresentou uma liberação de forma gradual e crescente, atingindo seu pico após 5 dias, mantendo-se constante durante 7 dias (Fig. 2 a).

Em contrapartida, visando uma liberação mais prolongada devido à maior reticulação da rede de hidrogel, houve a aplicação do cloreto de cálcio. Os resultados obtidos denotaram um prolongamento notável na liberação do antibiótico, atingindo sua maior quota em 7 dias, perpetuando a liberação de forma constante por até 11 dias (Fig. 2 b)

Figura 2 - Hidrogel com eritromicina sem adição de $\mathrm{CaCl}_{2}$, e o gráfico (B) com a adição de $\mathrm{CaCl}_{2}$.
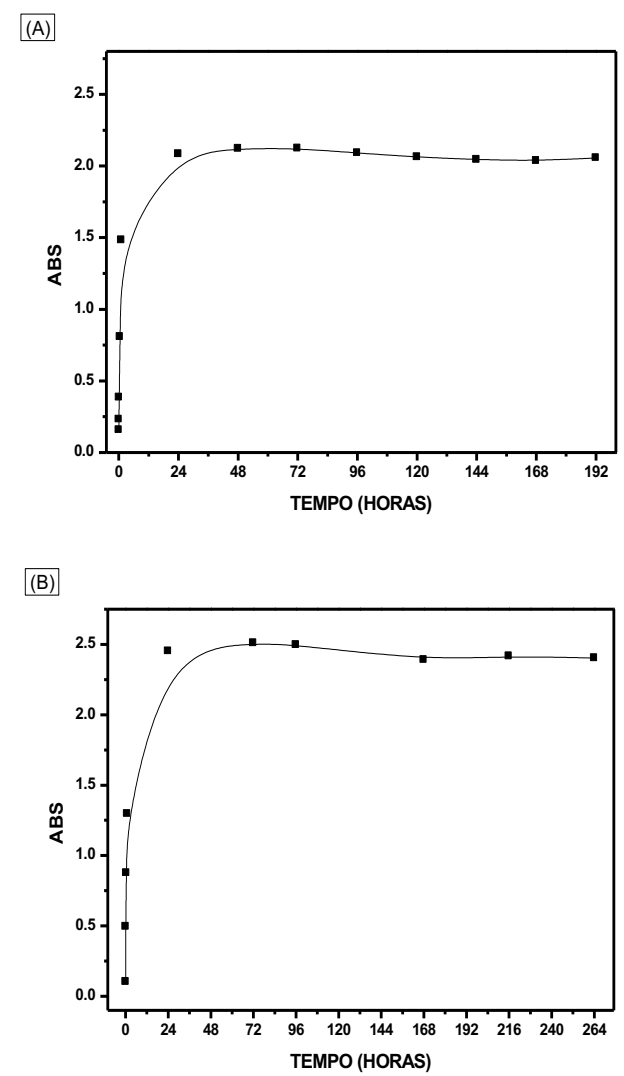

$\mathrm{Na}$ formação do hidrogel de alginato no método de ligação cruzada iônica, quando os blocos de manuronato e guluronato entram em contato com cátions divalentes como o $\mathrm{Ca}^{2+}$, permite a sua ligação formando uma estrutura tridimensional em rede 
chamada egg-box, o qual permite a incorporação de agentes antimicrobianos como o antibiótico eritromicina, onde as redes poliméricas agem como carreadores para um sistema de liberação controlada. Sua aplicação permite uma maior rigidez na malha polimérica, permitindo a liberação de moléculas como as do antibiótico de forma mais lenta e prolongada (ZHAO et al., 2014). A liberação de drogas com uma dosagem apropriada para um determinado intervalo de tempo é de extrema importância na eficácia do tratamento do paciente, principalmente no caso de antibióticos, o qual doses menores podem culminar na resistência dos microrganismos aos antimicrobianos aplicados e doses maiores acarretam em intoxicação (LEE et al., 2012).

\section{CONCLUSÃO}

O presente trabalho demonstrou o desenvolvimento de hidrogéis homogêneos para a encapsulação dos antibióticos. A cinética de liberação apresentou uma liberação crescente até 5 dias e contínua após 7 dias para o hidrogel com eritromicina, enquanto que o hidrogel na presença de cloreto de cálcio apresentou ampliação na liberação, atingindo seu ápice em 7 e liberação constante em até 11 dias. O sistema obtido se apresenta como excelente alternativa para uso tópico de ferimentos, visando cicatrização acelerada e redução da colonização por microrganismos.

\section{REFERÊNCIAS}

BHATIA, Saurabh. Natural Polymers vs Synthetic Polymer. In: Natural Polymer Drug Delivery Systems. Springer International Publishing, 2016. p. 95-118.

KOPEČEK, Jindřich; YANG, Jiyuan. Hydrogels as smart biomaterials. Polymer International, v. 56, n. 9, p. 1078-1098, 2007.

LEE, Kuen Yong; MOONEY, David J. Alginate: properties and biomedical applications. Progress in polymer science, v. 37, n. 1, p. 106-126, 2012.

MANJANNA, K. M.; RAJESH, K. S.; SHIVAKUMAR, B. Formulation and optimization of natural polysaccharide hydrogel microbeads of aceclofenac sodium for oral controlled drug delivery. American Journal of Medical Sciences and Medicine, v. 1, n. 1, p. 5-17, 2013

MOTA, Rinaldo Aparecido, et al. "Utilização indiscriminada de antimicrobianos e sua contribuição a multirresitência bacteriana." Brazilian Journal of Veterinary Research and Animal Science 42.6 (2005): 465-470

SILVEIRA, Gustavo Pozza, et al. "Estratégias utilizadas no combate a resistência bacteriana." Química Nova 29.4 (2006): 844.

ZHAO, Yu et al. In situ cross-linked polysaccharide hydrogel as extracellular matrix mimics for antibiotics delivery. Carbohydrate polymers, v. 105, p. 63-69, 2014.

\section{AGRADECIMENTOS}

Agradeço ao CNPq o fomento em pesquisa. 